\title{
Modeling of thermal process in the energy system "Electrical network - asynchronous motor"
}

\author{
Vitaliy Kuznetsov ${ }^{1, *}$, Mykola Tryputen ${ }^{2}$, Valerii Tytiuk ${ }^{3}$, Zhanna Rozhnenko ${ }^{3}$, Serhii Levchenko ${ }^{4}$, and Valeriy Kuznetsov $^{5}$ \\ ${ }^{1}$ National Metallurgical Academy of Ukraine, Department of the Electrical Engineering and Electromechanics, 4 Haharina Ave., Dnipro, \\ 49600, Ukraine \\ ${ }^{2}$ Dnipro University of Technology, Department of Automation and Instrumentation, 19 Dmytra Yavornytskoho Ave., Dnipro, 49005 , \\ Ukraine \\ ${ }^{3}$ Kryvyi Rih National University, Department of Electromechanics, 11 Vitalii Matusevych Str., Kryvyi Rih, 50027, Ukraine \\ ${ }^{4}$ Zaporizhzhya National University, Department of Electrical Engineering and Energy Efficiency, 66 Zhukovskoho Str., Zaporizhzhya, \\ 69600, Ukraine \\ ${ }^{5}$ Railway Research Institute, Electric Power Department, 50 Chlopickiego Str., 04-275 Warsaw, Poland
}

\begin{abstract}
The paper discusses the influence of low-quality electricity on the temperature modes of operation of an asynchronous motor. In the course of experimental and analytical studies, the heat transfer coefficients and heat capacity of a particular electromechanical converter were determined. Experimental and analytical dependences of temperature changes of an asynchronous motor on time are given when it is connected to a supply voltage with different coefficients of sinusoidal distortion and negative sequence. The resulting model is tested for its adequacy to the real process and can be used as an element in the energy-economic model of an asynchronous motor to assess its uptime. This model that can be useful for simulation of thermal processes in asynchronous motors and optimising these devices for increasing the reliability.
\end{abstract}

\section{Introduction}

The presence of low-quality electricity in the shop networks of industrial enterprises leads to a decrease in the main indicators of the operation of asynchronous motors (AM), their accelerated physical aging, and, as a consequence, the occurrence of emergency situations. It is advisable to formulate this problem in the technical and economic plane, and its solution requires a detailed consideration of the system "electrical network asynchronous motor" with the involvement of methods of mathematical modeling and implementation of computational experiments on a computer [1-3].

The economic assessment of various options for restoring electricity in shop networks to standard quality indicators is the basis proposed in [4-7] for a decisionmaking method for the operation of electrical equipment, including AM, operating in conditions of poor-quality supply voltage [8].

According to this methodology, according to the current indicators of the quality of electricity in the enterprise network [9-10] and on the basis of energy models [11-13] of the electromechanical converter, its energy indicators are calculated and the time interval of trouble-free operation.

In case of significant deviations of the indicators calculated in this way from the specified ones, various options for technical solutions for restoring the quality of the electric energy supplied to the engine are considered. For each of the options, a cost estimate is performed and a final decision is made on the conditions for its further work.

Wide experience in researching the effect of power quality on the operation of asynchronous motors with a has been accumulated by now [14-16].

Poor power quality in the workshops of industrial enterprises stipulates the increase in direct industrial costs due to the growing power consumption. Moreover, indirect costs related to the reduced operating life of electric machines are increasing as well.

As is known [10,11], normative operating life of the all-purpose asynchronous motors is about ten years. However, that is true only for the cases when certain conditions are observed. The main condition here is the correspondence of the thermal mode of an electric machine to the insulation class.

Deterioration of the power quality results in the increase of heating losses and insulation temperature respectively. Combined with the overloads, that results in the considerable reduction of the operating life of the electric motors. Practice shows that in terms of $40 \%$ of all-purpose AM with nominal voltage of $0.4 \mathrm{kV}$, the operating life is $1.25-2$ years [17].

The aim of the paper is to synthesize a mathematical model of an asynchronous motor, taking into account the influence of changes in the quality indicators of electricity on heating and heat transfer processes, for an economically justified choice of protective equipment.

\footnotetext{
$\overline{\text { * Corresponding author: wit1975@i.ua }}$
} 


\section{Materials and research results}

To study the effect of the operating modes of an electric motor on its thermal conditions, so-called thermal models are applied [18-21]. They are the equivalent circuits where electric losses act as the heat sources; temperatures of structural components are within the nodes; and corresponding heat conductivities and capacities are located between them.

The considered models have different degree of detalization. A single-mass model, in which an electromechanical transducer is represented as a single homogeneous body with the overall temperature, is the simplest one. Although, the real temperature distribution is not uniform: temperature of the AM stator winding may exceed the case temperature by $15-20^{\circ} \mathrm{C}[22,23]$.

More detailed models have minor prediction errors; however, that requires having additional data on heat conductivities and capacities of separate structural components of a motor. As a rule, such models are used only at the design stage. Besides, while applying those models, the transient-free thermal conditions are analyzed without consideration of their dynamics.

We consider that during the operation, it is the most expedient solution to use a single-mass thermal model; moreover, it is necessary to analyze the temperature of the AM component, being critical in terms of heating, - stator end winding - as the initial parameter of the model. It is well-known that this component is under the poorest cooling conditions since its thermal efficiency is effected mainly by means of the air.

A single-mass dynamic thermal model of the asynchronous motor is described by the following differential equation:

$$
\Delta P=A \cdot \tau+\frac{\Delta \tau}{\Delta t} \cdot C
$$

here $\Delta P$ is the power of heating losses generated in the electric motor; $\tau$ is the exceedance of the motor temperature over the surrounding temperature; $\Delta \tau$ is the increment of the motor temperature per time $\Delta t ; A$ is the coefficient of thermal efficiency, $\mathrm{J} /(\mathrm{sec} \cdot \mathrm{C}$ ) (equal to the radiation heat loss per $1 \mathrm{sec}$ in terms of the difference in the indicated temperatures $\tau=1{ }^{\circ} \mathrm{C}$ ); $C$ is the heat capacity of the motor, $\mathrm{J} /{ }^{\circ} \mathrm{C}$. The indicated heat capacity is equal to the amount of heat required for AM heating by $1{ }^{\circ} \mathrm{C}$ in terms of the nonavailable radiation heat loss.

As is obvious, equation of thermal balance (1) has two unknown values - A and $\mathrm{C}$, which may be defined with the help of experimental data by composing a system of equations relative to the unknowns. In this context, it is possible to improve the accuracy of determining a coefficient of thermal efficiency and heat capacity of a motor at the expense of the totals of parameters measured in several experiments:

$$
\left\{\begin{array}{l}
\frac{\sum \Delta P}{N}=A \cdot \sum \tau+\sum \frac{\Delta \tau}{\Delta t} \cdot C \\
\frac{\sum \Delta P \cdot \tau}{N}=A \cdot \sum \tau^{2}+\sum \frac{\Delta \tau}{\Delta t} \cdot \tau \cdot C
\end{array}\right.
$$

Corresponding experiments have been carried out in terms of experimental workshop of Ukrspetsservis Ltd.
Asynchronous motor of 4AX80A4Y3 type has been analyzed (nominal parameters are as follows: $\mathrm{U}_{\mathrm{n}}=220 / 380 \mathrm{~V}(\Delta / \mathrm{Y}), \quad \mathrm{P}_{\mathrm{n}}=1.1 \mathrm{~kW}, \quad \mathrm{n}_{\mathrm{n}}=1400 \mathrm{rot} / \mathrm{min}$, $\left.\mathrm{I}_{\mathrm{n}}=4.8 / 2.8 \mathrm{~A}, \eta=75 \%, \cos \varphi=0.81\right)$.

The motor is loaded on a direct-current generator of П31У4 type (nominal parameters are as follows: $\mathrm{U}_{\mathrm{n}}=230 \mathrm{~V}, \quad \mathrm{P}_{\mathrm{n}}=1.0 \mathrm{~kW}, \quad \mathrm{n}_{\mathrm{n}}=1450 \mathrm{rot} / \mathrm{min}, \mathrm{I}_{\mathrm{n}}=4.3 \mathrm{~A}$, $\eta=75 \%$ ). During the experiments, AM was heated under the nominal load; the cooling took place in terms of the non-rotating rotor.

A hole was made in the motor cover to determine the temperature of winding faces with the help of laser pyrometer of Fluke 568 type. The hole was open only for a short period for measuring $(5 \mathrm{sec})$; when the electric motor was operating, the hole was closed to prevent the heat exchange between the internal and external air. Currents and voltages were recorded with the help of a mobile measuring and diagnostic complex based on the current sensors of LA 25A type, voltage sensors LV100P (made by LEM, Switzerland), and AD converter E-440 (L-CARD, Russia). Table 1 shows the characteristics of the measuring channels.

Table 1. Characteristics of the measuring channels of a mobile measuring and diagnostic complex

\begin{tabular}{|c|c|}
\hline Component & Characteristics \\
\hline AD converter & E-440 \\
\hline TYPE & 16 differential ones \\
\hline Number of channels & $12 \mathrm{bits}$ \\
\hline Digit capacity & $1.7 \mathrm{mcs}$ \\
\hline Conversion time & $\pm 5.12 \mathrm{~V} ; \pm 2.56 \mathrm{~V} ; \pm 1.024 \mathrm{~V} ;$ \\
\hline Input range & $200 \mathrm{kHz}$ \\
\hline Maximum conversion frequency & $\pm 0.5 \mathrm{LOD} ; \mathrm{max}$ 1LOD. \\
\hline Zero shift & \\
\hline Voltage sensor & LV-400 \\
\hline TYPE & $0-500 \mathrm{~V}$ \\
\hline Input range & $0-10 \mathrm{~V}$ \\
\hline Output range & $0.015 \%$ \\
\hline Maximum static error & $0.03 \%$ \\
\hline Maximum dynamic error & \\
\hline Current sensor & LA-100 C \\
\hline TYPE & $0-250 \mathrm{~A}$ \\
\hline Input range & $0-10 \mathrm{~V}$ \\
\hline Output range & $0.03 \%$ \\
\hline Maximum static error & $0.08 \%$ \\
\hline Maximum dynamic error &
\end{tabular}

To eliminate the experiment error stipulated by the increased heating during the starting, the tested electric motor is accelerated with the help of a loading machine operating under the motoring conditions. Only when the facility reaches the idling speed, source voltage is supplied to the asynchronous motor, and a loading machine is placed in the dynamic braking mode (Fig. 1).

Table 2 represents the results of the experiment of test motor heating in terms of ideal supply voltage.

Fig. 2 shows the experimentally obtained curve of test motor heating in terms of ideal supply voltage.

Within the period of 62 minutes, the motor temperature has reached the final value of $76.3^{\circ} \mathrm{C}$. The experiment results have made it possible to compose a system of equations (2) and to calculate the parameters of 
a single-mass thermal model. The parameters are as follows: coefficient of the motor's thermal efficiency while rotating is $\mathrm{A}=11.2 \mathrm{~J} /\left(\mathrm{sec} \times{ }^{\circ} \mathrm{C}\right)$, heat capacity of the electric motor is $\mathrm{C}-12.1 \mathrm{~kJ} /{ }^{\circ} \mathrm{C}$.

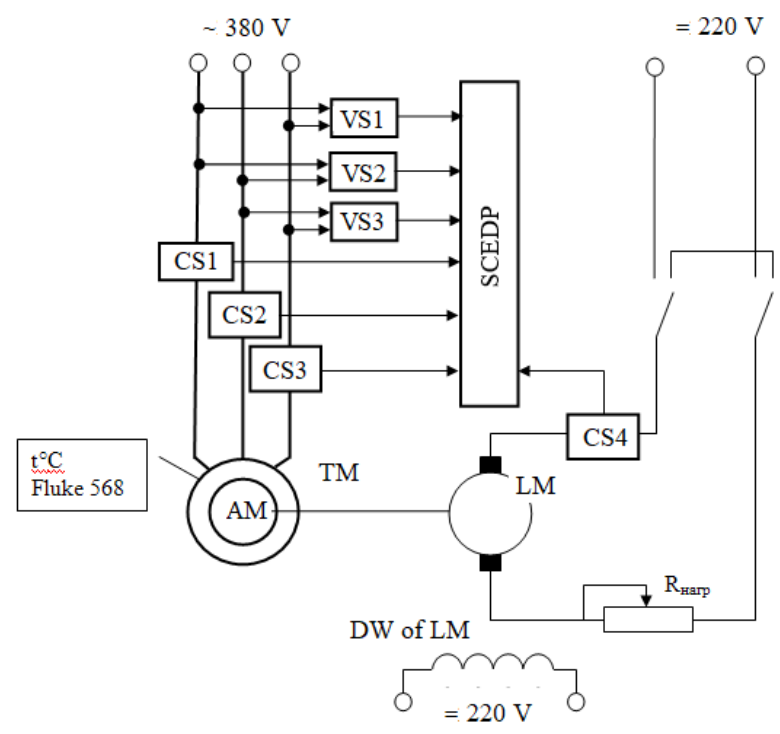

Fig. 1. Schematic of the experience to test adequacy of a thermal model of an asynchronous motor: TM, LM - test machine and loading machine; SCEDP- system to control electric drive parameters (measuring complex); VS - voltage sensor; CS - current sensor ; DW of LM - drive winding of loading machine.

Table 2. Results of experiment \#1, ideal supply voltage.

\begin{tabular}{|c|c|c|c|}
\hline Time, sec & $\begin{array}{c}\text { Effective } \\
\text { temperature } \\
\text { value, }{ }^{\circ} \mathbf{C}\end{array}$ & $\begin{array}{c}\text { Temperature value } \\
\text { predicted in terms } \\
\text { of the model, }{ }^{\circ} \mathbf{C}\end{array}$ & $\begin{array}{c}\text { Absolute } \\
\text { error, }{ }^{\circ} \mathbf{C}\end{array}$ \\
\hline 0 & 0.0 & 0 & 0 \\
\hline 120 & 5.4 & 6 & 1 \\
\hline 240 & 10.4 & 12 & 1 \\
\hline 360 & 12.0 & 17 & 5 \\
\hline 480 & 14.7 & 21 & 6 \\
\hline 600 & 26.1 & 25 & -1 \\
\hline 720 & 28.7 & 28 & 0 \\
\hline 840 & 34.7 & 31 & -3 \\
\hline 960 & 37.6 & 34 & -3 \\
\hline 1080 & 40.1 & 37 & -3 \\
\hline 1200 & 43.4 & 39 & -5 \\
\hline 1320 & 45.0 & 41 & -4 \\
\hline 1440 & 46,7 & 42 & -4 \\
\hline 1560 & 47.7 & 44 & -4 \\
\hline 1680 & 48.7 & 45 & -3 \\
\hline 1800 & 50.0 & 47 & -3 \\
\hline 1920 & 50.0 & 48 & -2 \\
\hline Final value & 75.7 & 73 & -2 \\
\hline
\end{tabular}

Taking into account the fact that the reference literature contains rather scarce data on thermal parameters of the electric machines (as a rule, there is only the information concerning thermal time constants for motors of certain classes and power ranges), the considered method of their determination while identifying a specific AM model is rather topical.

Further, the heating experiments were carried out in terms of different degrees of distortion of the electric motor supply voltage. The experimental results are represented in Tables 3 and 4.

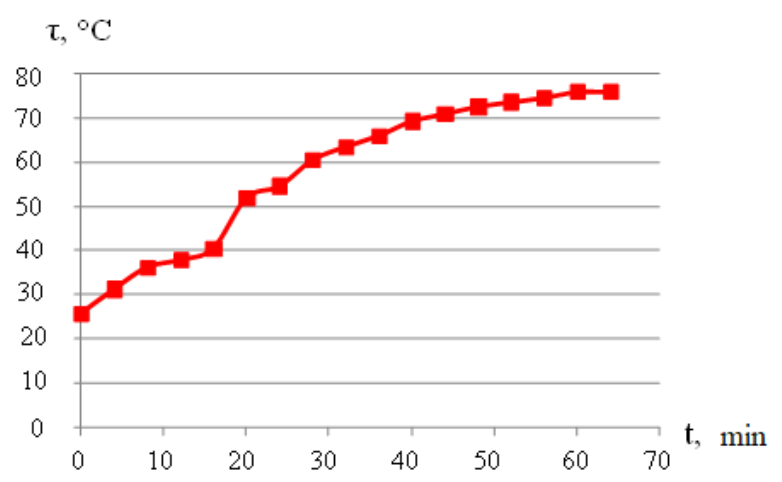

Fig. 2. Curve of motor heating while operating in terms of nominal load and ideal supply voltage.

Table 3. Results of experiment \#2, distorted supply voltage.

\begin{tabular}{|c|c|c|c|}
\hline Time, sec & $\begin{array}{c}\text { Effective } \\
\text { temperature } \\
\text { value, }{ }^{\circ} \mathbf{C}\end{array}$ & $\begin{array}{c}\text { Temperature value } \\
\text { predicted in terms } \\
\text { of the model, }{ }^{\circ} \mathbf{C}\end{array}$ & $\begin{array}{c}\text { Absolute } \\
\text { error, }{ }^{\circ} \mathbf{C}\end{array}$ \\
\hline 0 & 0.0 & 0 & 0.0 \\
\hline 120 & 12.0 & 12 & 0.1 \\
\hline 240 & 23.1 & 21 & 1.7 \\
\hline 360 & 30.8 & 29 & 1.6 \\
\hline 480 & 33.9 & 36 & -1.7 \\
\hline 600 & 38.7 & 41 & -2.0 \\
\hline 720 & 44.0 & 45 & -0.8 \\
\hline 840 & 44.3 & 48 & -3.9 \\
\hline 960 & 52.0 & 51 & 1.0 \\
\hline 1080 & 54.1 & 53 & 0.9 \\
\hline 1200 & 54.4 & 55 & -0.6 \\
\hline 1320 & 56.4 & 56 & 0.0 \\
\hline 1440 & 56.2 & 58 & -1.4 \\
\hline 1560 & 58.1 & 59 & -0.5 \\
\hline 1680 & 62.0 & 59 & 2.6 \\
\hline 1800 & 58.9 & 60 & -1.1 \\
\hline 1920 & 61.2 & 61 & 0.6 \\
\hline Final value & 86.0 & 86 & 0.0 \\
\hline
\end{tabular}

Table 4. Results of experiment \#3, distorted supply voltage.

\begin{tabular}{|c|c|c|c|}
\hline Time, sec & $\begin{array}{c}\text { Effective } \\
\text { temperature } \\
\text { value, }{ }^{\circ} \mathbf{C}\end{array}$ & $\begin{array}{c}\text { Temperature value } \\
\text { predicted in terms } \\
\text { of the model, }{ }^{\circ} \mathbf{C}\end{array}$ & $\begin{array}{c}\text { Absolute } \\
\text { error, }{ }^{\circ} \mathbf{C}\end{array}$ \\
\hline 0 & 0.0 & 0 & 0.0 \\
\hline 120 & 13.8 & 13 & 0.6 \\
\hline 240 & 21.9 & 24 & -2.1 \\
\hline 360 & 34.1 & 33 & 1.5 \\
\hline 480 & 37.8 & 40 & -1.9 \\
\hline 600 & 46.9 & 45 & 1.5 \\
\hline 720 & 47.9 & 50 & -2.1 \\
\hline 840 & 55.5 & 54 & 1.7 \\
\hline 960 & 55.3 & 57 & -1.6 \\
\hline 1080 & 60.3 & 59 & 0.9 \\
\hline 1200 & 61.1 & 61 & -0.2 \\
\hline 1320 & 64.3 & 63 & 1.4 \\
\hline 1440 & 65.5 & 64 & 1.2 \\
\hline 1560 & 62.8 & 65 & -2.6 \\
\hline 1680 & 62.8 & 66 & -3.4 \\
\hline 1800 & 69.7 & 67 & 2.8 \\
\hline 1920 & 68.1 & 68 & 0.6 \\
\hline Final value & 93.0 & 93 & 0.0 \\
\hline
\end{tabular}


Further experiments \#2-4 were carried out in terms of different degrees of distortion of electric motor power supply. The quality indices of the latter (coefficient of distortion of the sinusoidal voltage curve $\mathrm{k}_{\mathrm{U}}$, coefficient of voltage unsymmetry on the reverse sequence $\varepsilon_{2}$ ) are given in Table 5.

Table 5. Power quality indices in the experiments and final temperature values of the AM winding.

\begin{tabular}{|c|c|c|c|}
\hline $\begin{array}{c}\text { Experiment } \\
\text { No. }\end{array}$ & $\begin{array}{c}\text { Coefficient of } \\
\text { distortion of } \\
\text { the sinusoidal } \\
\text { voltage curve } \\
\mathbf{k}_{\mathbf{U}, \%} \%\end{array}$ & $\begin{array}{c}\text { Coefficient of } \\
\text { voltage } \\
\text { unsymmetry on } \\
\text { the reverse } \\
\text { sequence } \\
\mathbf{\varepsilon}_{\mathbf{2}} \mathbf{\%} \%\end{array}$ & $\begin{array}{c}\text { Final absolute } \\
\text { temperature, } \\
\boldsymbol{\tau}^{\circ} \mathbf{C}\end{array}$ \\
\hline 1 & 0 & 0 & 76.3 \\
\hline 2 & 0 & 4 & 85.1 \\
\hline 3 & 8 & 0 & 92.5 \\
\hline 4 & 13.0 & 0 & 117.8 \\
\hline
\end{tabular}

Experience \#4 corresponds to the motor operation with the temperature exceeding the admissible one for that insulation class $\mathrm{F}\left(105^{\circ} \mathrm{C}\right)$; $\mathrm{AM}$ may be in such a state only for a short period of time due to the possibility of thermal breakdown of its windings.

The considered experiments have been used to test the adequacy of the proposed AM dynamic thermal model. Figures 3-5 show the comparison of the graphs of temperature exceedance of the motor over the surrounding temperature in those heating experiments with the calculated curves obtained with the help of electrochemical and thermal model of an asynchronous motor [24-26].

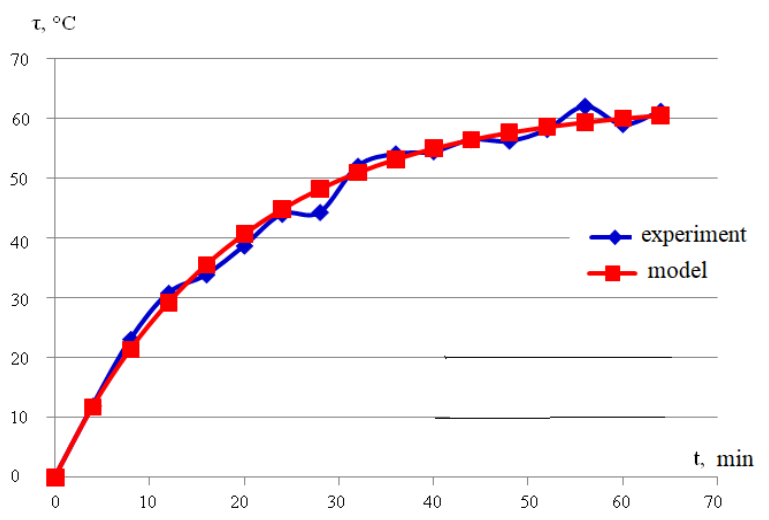

Fig. 3. Curves of motor heating in experiment \# 2 .

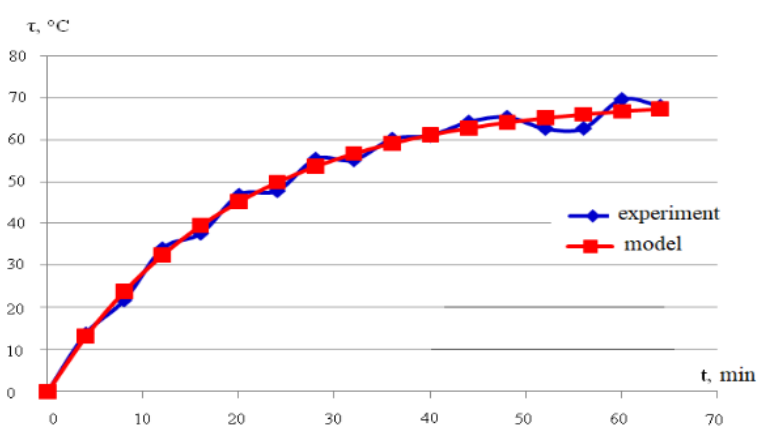

Fig. 4. Curves of motor heating in experiment \# 3 .

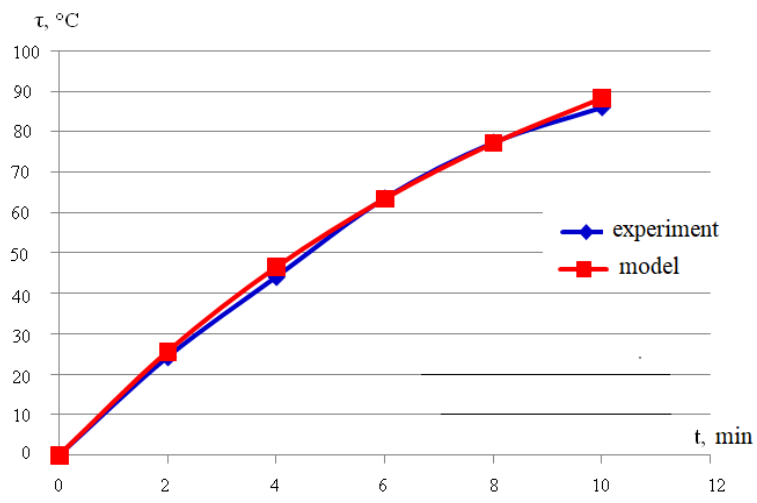

Fig. 5. Curves of motor heating in experiment \# 4.

Next, error of the predicted temperature value in the heating dynamics was calculated. Fig. 6 demonstrates the experimental and calculated (predicted) temperature values for all the performed experiments which are used to test the model adequacy according to the method represented in [27-29]. In this context, different format of markers belongs to the corresponding experiments.

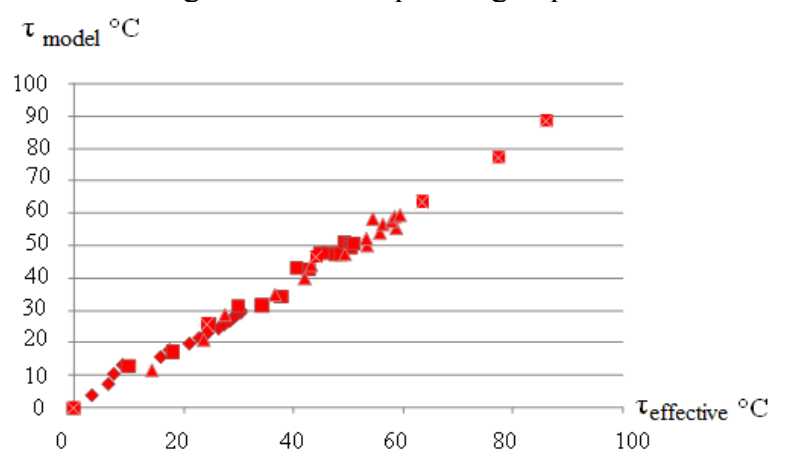

Fig. 6. Relations of the predicted $\tau_{M}$ and experimental $\tau_{e f}$ values of the temperature exceedance of AM winding.

The carried out test for the adequacy supposes obtaining of the following equation of linear regression:

$$
Y_{n}^{*}=a_{0}+a_{1} Y_{e f}
$$

where

$$
a_{0}=\overline{Y_{n}}-r_{Y_{e f} Y_{n}} \frac{\sigma_{Y_{n}}}{\sigma_{Y_{e f}}} \overline{Y_{e f}} ; \quad a_{1}=r_{Y_{e f} Y_{n}} \frac{\sigma_{Y_{n}}}{\sigma_{Y_{e f}}}
$$

Here, $\overline{Y_{n}}, \overline{Y_{e f}}$ are the average values of the predicted and effective values; $r_{Y_{e f} Y_{n}}$ is the coefficient of correlation between them; $\sigma_{Y_{n}}, \sigma_{Y_{e f}}$ are the mean square deviations.

The indicated parameters were calculated according to the formulas:

$$
\begin{gathered}
r_{Y_{e f} Y_{n}}=\frac{\sum_{1}^{L}\left(Y_{e f}-\overline{Y_{e f}}\right)\left(Y_{n}-\overline{Y_{n}}\right)}{L \sigma_{Y_{e f}} \sigma_{Y_{n}}}, \\
\sigma_{Y_{e f}}=\sqrt{\sum_{1}^{L}\left(Y_{e f}-\overline{Y_{e f}}\right)^{2} /(L-1)}, \\
\sigma_{Y_{n}}=\sqrt{\sum_{1}^{L}\left(Y_{n}-\overline{Y_{n}}\right)^{2} /(L-1)},
\end{gathered}
$$


where $L=57$ is the volume of statistic sampling (number of the temperature measurements in all the experiments).

The mean square absolute error of measurements was determined as:

$$
\Delta Y_{n}=t_{p} \sigma_{Y_{n}}^{*}
$$

where $t_{p}$ is the Student's coefficient for the given reliability and number of freedom degrees $k=L-1$. In the case under consideration, reliability was taken as $p=$ 0.05. Here, $\sigma_{Y_{n}}^{*}$ is the residual mean square deviation calculated according to the formula:

$$
\sigma_{Y_{n}}^{*}=\sqrt{\sum_{1}^{L}\left(Y_{n}-Y_{n}^{*}\right)^{2} /(L-1)} .
$$

The mean square relative error of prediction was determined as follows:

$$
\delta_{Y_{n}}=\left|\Delta Y_{n}\right| / Y_{n \max }
$$

where $Y_{n \text { max }}$ is the highest value of the predicted one.

Finally, the obtained values are as follows:

$\sigma_{\text {Yef }}=21.2^{\circ} \mathrm{C}, \sigma_{Y_{\Pi}}=20.9^{\circ} \mathrm{C}, \mathrm{r}_{Y_{\text {efY }}}=0.99$,

$\sigma^{*}{ }_{\mathrm{Yn}}=2.34{ }^{\circ} \mathrm{C}, \Delta \mathrm{Y}_{\mathrm{n}}=0.28{ }^{\circ} \mathrm{C}, \delta_{\mathrm{Yn}}=3.2 \%$.

\section{Conclusion}

The obtained results show the adequacy of the proposed thermal model of an asynchronous motor operating in the mains with poor quality power. Taking into consideration the fact that in terms of many motor types, reference literature does not contain the required data on the coefficients of thermal efficiency and thermal capacity, and only thermal constants of time are given for certain motor types, values of the specified parameters of the model may be obtained basing on the methodology represented in the paper.

\section{References}

1. A. Boglietti, A. Cavagnino, M. Lazzari and A. Pastorelli, A simplified thermal model for variable speed self cooled industrial induction motor, in 2002 IEEE Industry Applications Conference. 37th IAS Annual Meeting, Pittsburgh, PA, USA, 2002, vol. 2, pp. 723-730. doi:10.1109/IAS.2002.1042640.

2. O.I. Okoro, B. Weidemann, O. Ojo, An efficient thermal model for induction machines, in Industry Applications Conference 2004. 39th IAS Annual Meeting, 2004, vol. 4, pp. 2477-2484.

3. Kuznetsov, V., Nikolenko, A. Models of operating asynchronous engines at poor-quality electricity. Eastern-European Journal of Enterprise Technologies 1(8), 37-42 (2015)

4. V. Kuznetsov, M. Tryputen, Y. Kuznetsova, M. Babyak, V. Artemchuk, M. Kovzel, Ways to Improve Power Quality under the Conditions of Industrial Enterprises, in 2020 IEEE Problems of Automated Electrodrive. Theory and Practice (PAEP),
Kremenchuk, Ukraine, 2020, pp. 1-6, doi:10.1109/PAEP49887.2020.9240801.

5. I. Lutsenko et al., Development of a method for structural optimization of a neural network based on the criterion of resource utilization efficiency. Eastern-European Journal of Enterprise Technologies 2(4(98)) (2019). doi:10.15587/17294061.2019.164591

6. O. Mykhailenko, Ore crushing process dynamics modeling using the Laguerre model. EasternEuropean Journal of Enterprise Technologies 4(4(76)) (2015). doi:10.15587/17294061.2015.47318

7. M. Tryputen, V. Kuznetsov, A. Kuznetsova, M. Tryputen, Y. Kuznetsova, T. Serdiuk, "Improving the Reliability of Simulating the Operation of an Induction Motor in Solving the Technical and Economic Problem", in: Hu Z., Petoukhov S., Dychka I., He M. (eds) Advances in Computer Science for Engineering and Education III. ICCSEEA 2020. Advances in Intelligent Systems and Computing, vol 1247. (Springer, Cham, 2021). doi:10.1007/978-3-030-55506-1_13

8. O. Mykhailenko, Research of adaptive algorithms of Laguerre model parametrical identification at approximation of ore breaking process dynamics. Metallurgical and Mining Industry 6, 109-117 (2015)

9. A. Uskov, V. Shchokin, O. Mykhailenko, O. Kryvenko, The fuzzy logic controllers synthesis method in the vector control system of the wind turbine doubly-fed induction generator. E3S Web of Conferences 166, $04006 \quad$ (2020). doi:10.1051/e3sconf/202016604006.

10. DSTU EN 50160:2014. Characteristics of electric energy supply voltage in general-purpose electric networks (2014)

11. GOST 13109-97. Normy kachestva jelektricheskoj jenergii $v$ sistemah jelektrosnabzhenija obshhego naznachenija. IPK (Izdatel'stvo standartov, Moscow, 1998)

12. O.V. Kyrylenko, Modeling of energy processes in energy supply systems in solving energy saving problems. Pratsi Instytutu elektrodynamiky NAN Ukrainy, Elektrodynamika, 87-91 (2001)

13. Y.V. Zhezhelenko, Electricity quality indicators and their control at industrial enterprises (Energoatomizdat, Moskva, 2000)

14. C. Mastorocostas, I. Kioskeridis, N. Margaris, Thermal and slip effects on rotor time constant in vector controlled induction motor drives. IEEE Transactions on Power Electronics 21(2), 495-504 (2006). doi:10.1109/TPEL.2005.869765

15. J. P. Bastos, M. F. R. R. Cabreira, N. Sadowski, S. R. Arruda, S. L. Nau, A thermal analysis of induction motors using a weak coupled modeling. IEEE Transactions on Magnetics 33(2), 1714-1717 (1997). doi: $10.1109 / 20.582603$ 
16. D. G. Nair, T. Jokinen, A. Arkkio, Coupled analytical and $3 \mathrm{D}$ numerical thermal analysis of a TEFC induction motor, in 2015 18th International Conference on Electrical Machines and Systems (ICEMS), Pattaya, 2015, pp. 103-108. doi:10.1109/ICEMS.2015.7385008.

17. P. Chystiakov, O. Chornyi, B. Zhautikov, G. Sivyakova, Remote control of electromechanical systems based on computer simulators, in 2017 International Conference on Modern Electrical and Energy Systems (MEES), Kremenchuk, 2017, pp. 364-367. doi:10.1109/MEES.2017.8248934

18. A. Tuys, F. Meyer, M. Steichen, C. Zwyssig, J.W. Kolar, Advanced Cooling Methods for High-Speed Electrical Machines. IEEE Transactions on Industry Applications 53(3), 2077-2087 (2017)

19. M. Schrittwieser, A. Marn, E. Farnleitner, G. Kastner, Numerical analysis of heat transfer and flow of stator duct models. IEEE Trans. Ind. Appl. 50(1), 226-233 (2014)

20. S. E. Zocholl, E. O. Schweitzer, A. Aliaga-Zegarra, Thermal Protection of Induction Motors Enhanced by Interactive Electrical and Thermal Models. IEEE Transactions on Power Apparatus and Systems PAS103(7), 1749-1755 (1984). doi:10.1109/TPAS.1984.318678.

21. M. Kotsur, I. Kotsur, Y. Bezverkhnia, D. Andrienko, Increasing of thermal reliability of a regulated induction motor in non-standard cycle time conditions, in 2017 International Conference on Modern Electrical and Energy Systems (MEES), Kremenchuk, 2017, pp. 88-91, doi:10.1109/MEES.2017.8248960.

22. A. Boglietti, A. Cavagnino, D. Staton, Determination of critical parameters in electrical machine thermal models. IEEE Trans. Ind. Appl. 44(4), 1150-1159 (2008)

23. A.N. Eliasen, The Protection of High-Inertia Drive Motors During Abnormal Starting Conditions. IEEE Transactions PAS-99 (4) (1980)

24. A. Boglietti, A. Cavagnino, D. Staton, M. Shanel, M. Mueller, C. Mejuto, Evolution and modern approaches for thermal analysis of electrical machines. IEEE Trans. Ind. Electron. 56(3), 871-882 (2009)

25. M. Zagirnyak, D. Mamchur, A. Kalinov, An algorithm for induction motor monitoring system based on electrical signals analysis. Przeglad Elektrotechniczny 94(6), 15-18 (2018)

26. A. Kluczek, P. Olszewski, Energy audits in industrial processes. Journal of Cleaner Production 142(4), 3437-3453 (2017)

27. Y. Adler, Planning an experiment in finding optimal conditions (Nauka, Moscow, 1976)

28. B. Ivobotenko, I. Iliinskyi, I. Kopylov, Experiment planning in electromechanics (Energiya, Moscow, 1975)
29. G. Korn, Mathematics Handbook for Scientists and Engineers: Definitions, Theorems, Formulas (Book on Demand, Moscow, 2014) 